\title{
A perceptual study of the wh-island constraint in Seoul Korean
}

\author{
Weonhee Yun* \\ Department of English Language and Literature, Keimyung University, Daegu, Korea
}

\begin{abstract}
This study investigated the status of the wh-island constraint in Seoul Korean. The syntactic movement of a wh-phrase out of an embedded sentence so as to have wide scope at LF is known to be invalid as it violates the wh-island constraint, but there have been studies in which such a movement was possible when the sentence is read with a wh-intonation. We conducted perceptual tests in which subjects were asked to select an answer after listening to each of the four types of interrogative sentences. Three of them were with 'Nugu-leul', which is an accusative form of the wh-phrase 'who' as well as an indefinite form. The fourth sentence contained the name of a person. 'Nugu-leul' and the noun were positioned in the same embedded sentence to see whether the subjects accepted a matrix scope interpretation of the wh-phrases. Response time was transformed to normalized log response time and checked to find any differences in the time taken to select the answers depending on different types of interrogative sentences. The results showed the subjects had a definite preference for the matrix scope interpretation for the sentences with a wh-intonation. The response time required to select the matrix scope interpretation was longer than for any other type of interrogative sentence. We concluded that the wh-island constraint in Seoul Korean is weak.
\end{abstract}

Keywords: syntax-phonology interface, wh-intonation, wh-scope, response time, wh-island constraint, perception test

\section{1. 서론}

이 연구는 Park et al.(2020)에서 다루어진 의문사 구(wh-phrase) 가 내포문(embedded sentence)에 포함된 의문문의 종류, 즉 판정 의문문(yes/no question)인지 또는 설명 의문문(wh question)인지 를 판별하는 지각 실험의 결과 중, 지난 연구에서 다루지 않은 서울말의 실험 결과를 분석하는 것이다. 이를 통하여 통사 현상 으로 알려져 있는 wh-섬 제약(wh-island constraint)이 서울말에 서 약화되는지 논의해 보고자 한다. wh-섬 제약이란 내포문이 간접 의문문을 형성할 때 그 내부
의 의문사 구가 문두로 이동하는 것을 허락하지 않는 현상을 일 컫는다. 영어와 같이 명시적 이동(overt movement)이 일어나는 언어와 달리 의문사 이동이 외현적으로 나타나지 않는 'wh-in-situ' 언어인 한국어는 의문사 구의 작용역(wh-scope) 위 치 이동이 논리 형태(logical form)에서 '보이지 않는 이동(covert movement)'으로 나타난다고 알려져 있다(Huang, 1982). 비록 보 이지 않는 이동이라 할지라도 섬 제약 상황에 놓이게 되면, 즉 내포문의 의문사 구가 모문 작용역(matrix scope)으로 해석되기 위해 모문(matrix sentence)으로 이동하는 것은 섬 제약 위반이 며 따라서 비문으로 간주된다. 그러나 만약 내포문에 의문사 구

\footnotetext{
*whyun@kmu.ac.kr, Corresponding author Received 4 June 2021; Revised 20 June 2021; Accepted 21 June 2021

(c) Copyright 2021 Korean Society of Speech Sciences. This is an Open-Access article distributed under the terms of the Creative Commons Attribution NonCommercial License (http://creativecommons.org/licenses/by-nc/4.0) which permits unrestricted non-commercial use, distribution, and reproduction in any medium, provided the original work is properly cited.
} 
가 있는 의문문이 설명 의문문으로 판단된다면 해당 의문사 구 가 모문 작용역을 갖는 것으로 해석되며, 이는 wh-섬 제약이 한 국어에 실재 하는지, 존재한다면 왜 약화되는지 등, wh-섬 제약 에 대한 전반적인 재해석을 요구하게 된다.

이 연구는 서울말에서 모문 작용역으로 해석될 수 있는 운율 구조를 가진 자극 문장을 얼마나 많은 피험자들이 의도된 작용 역으로 판단하는지, 그리고 지각 반응 시간을 통하여 내포문 작 용역과 모문 작용역의 판단에 소요된 시간이 어떤 차이를 보이 는지 살펴보고 지각 측면에서 전반적인 wh-섬 제약의 발현 양 상에 대하여 논의해 보고자 한다.

\section{2. 선행 연구}

$\operatorname{Ross}(1967)$ 는 특정 통사 구조(섬 제약 구조)에서 의문사 구의 이동이 불가함을 주장하였다. 그러나 명시적이든 보이지 않는 이동이든, 이동의 종류와 관계없이 의문사 이동이 불가한 것으 로 알려진 구조에서도 때에 따라 섬 제약이 약화되는 경우가 보 고되었다(Chung, 1996; Miyagawa, 2004). Ishihara(2002, 2004)와 Deguchi \& Kitagawa(2002)는 일본어에서 특정 운율 패턴을 사용 하여 읽을 경우 모문 작용역으로 해석된다고 주장하였다.

한국어, 특히 동남 방언에서 내포문에 의문사 구가 있을 경우 그 의문사 구의 작용역은 내포문으로도 모문으로도 해석할 수 있다. 이는 모문의 의문 종결어미가 ‘-나'(판정 의문문), ‘-노'(설 명 의문문)의 차이로 나타나기 때문에 작용역의 구분이 가능하 며, 이러한 이유로 섬 제약 약화의 예로 사용되었다(Suh, 1987). 즉 의문 종결어미가 ‘-나’로 끝날 경우 판정 의문문이므로 내포 문의 의문사 구는 내포문 작용역을 나타내고, 모문의 종결 어미 가 ‘-노’로 끝날 경우 설명 의문문이므로 내포문 의문사 구는 모 문 작용역으로 해석된다. 이러한 형태적 차이는 발화시 문장의 피치 곡선(pitch contour)에서도 작용역에 따라 소위 의문사 억 양(wh-intonation)'이라는 특정 운율 구조로 나타난다(Hwang, 2006, 2007, 2011, 2015; Jung, 2010; Kubo, 2005; Lee, 2001; Yun et al., 2020).

Hwang(2015)에서 동남 방언(경남) 모문 작용역을 나타내는 두 가지 피치 곡선 형태를 제시하고 각각의 형태에 상응하는 운 율 음향 단서가 있다고 주장하였다. 그러나 동일한 모문 작용역 임에도 피치 곡선의 패턴에 따라 서로 다른 음향 단서를 사용한 다는 것은 효과적이라고 할 수 없다. 이에 Yun et al.(2020)에서 는 동일한 운율 단서를 활용하여 작용역을 구분할 수 있음을 밝 혔다. 즉 보문소(complementizer)를 포함한 내포문 동사가 나타 내는 F0 변동 폭이 모문 작용역일 때 작고 내포문 작용역일 때 크며, 의문 종결어미를 포함한 모문 동사의 F0 변동 폭도 모문 작용역에서 내포문 작용역일 경우보다 작게 나타났다고 주장 하였다.

이러한 결과는 Yun(2019)의 주장과 유사성을 보여주고 있는
데, 서울말을 대상으로 한 청취 실험에서 의문문 지각 요인은 의문사 구 뒤에서 운율 경계의 해지(post-wh dephrasing)로 나타 나며, 의문사 구가 형태적으로는 동일하나 부정 대명사(whindefinite)로 사용될 경우 그것의 돋들림(prominence or pitch raising)이 이 wh-부정 대명사를 모문 작용역으로 해석할 가능성 을 증가시킨다는 것이다. 비록 이 연구의 실험에 사용된 문장은 wh-섬 제약을 일으키지 않는 조건절에서의 의문사 구(또는 동 일 형태의 wh-부정 대명사)를 대상으로 하였으나 아래 두 가지 면에서 동남 방언 wh-섬 제약 문장의 의문사 작용역 구분에서 도 나타나는 동일한 현상이라 할 수 있다. ${ }^{1}$

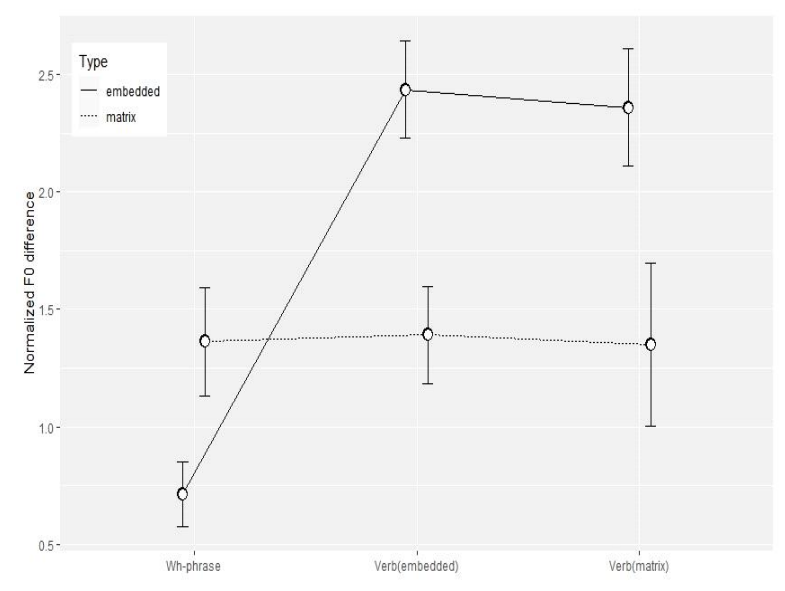

Adapted from Yun et al. (2020: 49) with permission of author.

그림 1. 작용역에 따른 의문사 어구, 내포문 동사, 모문 동사의 F0 정점과 끝 지점 $\mathrm{F} 0$ 의 표준화된 변동 폭에 대한 평균과 \pm 1 표준 편차.

Figure 1. Means and \pm 1 standard deviation of normalized F0 difference between F0 at the end of the three words and the peak F0 of the word in the embedded and matrix wh-scope sentences.

첫째, 운율 경계의 해지란 의문사 구 이후의 강세구(accentual phrase)에 확연한 강세구 운율이 나타나지 않는 것을 의미하며 이를 보여주는 음향 단서는 의문사 구 이후의 어절에서 구해지 는 F0 변동 폭이 강세구가 확연한 문장에서 구해지는 F0 변동 폭보다 상대적으로 작다는 것이다. Yun(2019)은 운율 경계 해지 의 범위가 Richards(2010)에서 주장하듯이 해당 의문사 구와 상 응하는 보문소까지로 보았으므로 만약 의문사 구가 모문 작용 역을 갖는다면 운율 경계의 해지는 모문 동사와 의문 종결어미 를 포함한 문장의 마지막 어절의 F0 변동 폭도 강세구(이 경우 는 억양구(intonational phrase))에 나타나는 변동 폭보다 작다고 할 수 있다.

둘째, 모문 작용역일 경우 돋들림 현상은 그것이 wh-부정 대 명사가 아니라 의문사일 경우에도 동일하게 나타나는데, 모문 작용역인 의문사 구의 F0 변동 폭은 내포문 작용역 의문사 구의 F0 변동 폭보다 더 크게 나타나는 것이 일관되게 관찰되기 때문

1 실험에 사용된 자극 문장은 ‘이 약에 뭐가 들어가면 위험해’이며 ‘뭐’는 조건절에 위치하여 섬 제약과 무관하다고 밝히고 있다(Yun, 2019:634). 
이다. 이런 두 가지 공통점은 내포문 작용역 문장 ‘니는 영미가 누구를 좋아하는지 궁금하나?’와 모문 작용역 문장 ‘니는 영미 가 누구를 좋아하는지 궁금하노?’를 녹음한 자료에서 F0 변동 폭을 구하여 나타낸 그림 1을 통해 잘 보여주고 있다. 즉 의문사 구에서의 F0 변동 폭은 모문 작용역 문장에서 더 크게 나타나며 내포문 동사와 모문 동사가 있는 각각의 어절에서 구해지는 F0 변동 폭은 운율 경계 해지가 있는 모문 작용역 문장에서 더 작 게 나타남을 확인할 수 있다(Yun et al., 2020: 49).

두 연구 결과의 유사성에도 불구하고 근본적인 차이는 문장 이 상이함은 차치하고라도 Yun(2019)은 서울말을 Yun et al.(2020)은 동남 방언(경북)을 대상으로 했다는 점이며, 동남 방 언에서 발견된 서울말과의 동질성이 정작 서울말 화자들의 동 남 방언 실험 문장에 대응하는 서울말 문장 발화 실험에서 발견 되지 않거나 매우 미약하게 나타난다는 것이다(Yun et al., 2020: 50). 주지하듯이, 동남 방언과는 달리 서울말에는 의문 종결어 미가 설명 의문문인지 판정 의문문인지와 관계없이 모두 동일 한 형태로 나타나므로 동남 방언에서와 같이 모문 작용역 해석 이 근원적으로 불가능할 것이라 이해되었고 여러 연구에서 이 러한 문장의 비문법성을 지적하였다(Choe, 1995; Chung, 1996; Hong, 2004).

그러나 동남 방언에서와 같이 서울말에 적용될 수 있는 특정 운율 구조로 자극을 만들어 청취 지각 실험을 한다면 모문 작용 역 해석이 가능할 것으로 예측할 수 있고, 이에 Hwang(2007)과 Yoon(2010)은 서울말에서도 적절한 운율로 읽힌 문장의 지각 실험에서 모문 작용역으로 이해될 수 있다는 결과를 보여주었 다. 그러나 Hwang(2007)은 6명의 피험자를 대상으로 한 소규모 의 실험이었으며, Yoon(2010)은 41명의 피험자를 대상으로 하 였으나 피험자들이 청취와 동시에 자극 문장의 스크립트를 읽 도록 하는 다소 이해하기 어려운 실험 방법을 사용하였고 실험 설계가 청취 지각 실험에서의 일반적인 기술 방식을 따르지 않 는 취약점이 발견된다는 점에서 실험의 결과를 신뢰하는데 한 계가 있는 것으로 판단된다. 특히 모문 작용역의 운율 특징을 단지 의문 종결 어미의 피치 패턴으로만 해석하는 등의 오류도 발견된다. 실험 결과 측면에서도 Yoon(2010)이 주장하듯 모문 작용역으로 이해될 수 있는 자극에 대하여 단지 $33.8 \%$ 만의 피 험자가 모문 작용역으로 이해했다고 보고하고 있다. 이는 한국 어의 wh-섬 제약이 비교적 많은 사람들에게서(66.2\%) 여전히 제약으로 작용하는 결과를 나타내는 것으로, 자극 문장에 나타 난 운율 구조가 정말로 모문 작용역으로 해석할 수 있는 운율 구조를 가졌는지에 대한 의구심을 들게 한다.

이런 면에서 이 연구는 적절한 규모의 피험자를 선정, 지각 실험용 소프트웨어를 활용하고 3회 반복하는 일반적 방법론을 채택하여 결과에 대한 신뢰성을 확보하고자 하였으며, 자극 문 장의 운율 구조를 공개하여 그 타당성을 입증하려 하였다. 이를
통해, 서울말에서 모문 작용역 해석이 가능한지, 또 그것이 가 능하다면 내포문 작용역 해석이 선호됨에도 불구하고 얼마나 많은 피험자들이 모문 작용역으로 이해하는지, 그리고 각 자극 에 대한 반응 시간을 바탕으로 모문 작용역 판단에 얼마나 많은 부하(load)가 상대적으로 나타나는지를 살펴보고자 한다. 결과 적으로 서울말에서 wh-섬 제약이 실재하는지 또는 약화되는지 등 wh-섬 제약에 대한 전반적 재해석을 시도하고자 한다. ${ }^{2}$

\section{3. 실험 방법}

\section{1. 실험 참가자 및 자극 문장}

이 연구는 동남 방언(경북)과 서울말을 대상으로 한 Park et al.(2020)의 실험 결과를 바탕으로, 지난 연구에서 본격적으로 다루어지지 않은 서울말 실험에 대한 분석이므로 전체 실험 방 법 기술보다 이 연구에서 살펴보고자 하는 문장을 중심으로 기 술하고자 한다. 먼저 피험자는 총 50 명이며 부모님 포함 모두 서울, 인천, 경기권 출신으로 실험 당시(2018년) 나이는 평균 25.14 세, 표준편차는 3.25 이다. 피험자 중 80 년대 출생 $(84,85$, $86,89)$ 4명 그리고 가장 나이가 많은 피험자 79년생 1명이 포함 되었다. 피험자는 모두 실험 당시 대학 또는 대학원에 다니고 있었으며 청각, 말장애가 보고된 바 없다.

표1. 청취 실험 자극 문장과 의문사 구 해석 형태

Table 1. Sentences for stimuli and interpretations of wh-phrases

\begin{tabular}{c|c}
\hline & 궁금하다 \\
\hline 모문 작용역 & 너는 영미가 누구를 좋아하는지 궁금하니? \\
\hline 내포문 작용역 & 너는 영미가 누구를 좋아하는지 궁금하니? \\
\hline 부정 대명사 & 너는 영미가 누구를 좋아하는지 궁금하니? \\
\hline 명사 & 너는 영미가 민호를 좋아하는지 궁금하니? \\
\hline
\end{tabular}

청취 실험은 OpenSesame(Mathôt et al., 2012)를 사용하였으 며, 표 1 과 같이 네 개의 문장을 중심으로 추가적으로 동사 ‘생 각하다'로 이루어진 세 개의 문장, 즉 부정 대명사로 그리고 모 문의 작용역으로 사용되는 '너는 영미가 누구를 좋아한다고 생 각하니?’와, 명사구를 포함한 ‘너는 영미가 민호를 좋아한다고 생각하니?'를 자극 문장으로 선정하였다. '생각하다'는 교량 동 사(bridge verb)이므로 내포문 작용역 해석이 불가하여 총 7개 문장의 목표 자극 문장과 채움 문장(filler sentence) 32 개 문장, 전체 39 개 문장이 청취 실험 1 회를 이루고 있으며 이러한 실험 을 3 회 반복하였다. 채움 문장은 단순 판정 의문문과 누구, 왜, 어디, 무엇, 몇 등의 의문사가 들어간 설명 의문문으로 이루어 져 있다.

2 물론 이러한 원인이 통사적 제약의 재분석을 통하여 가능할 수 있으며 섬 제약 약화에 대한 통사적 재해석은 Yun et al.(2020)의 발화 실험을 통사 적으로 해석한 $\mathrm{Um} \& \mathrm{Kim}(2020)$ 과 $\mathrm{Kim} \& \mathrm{Um}(2020)$ 에서 찾을 수 있다. 
3.2. 자극 문장의 녹음과 피치 특성

자극 문장은 서울 출신의 50 대 남성이 녹음하였다. 주지하다 시피, 명사구가 포함된 문장을 제외하고 모두 동일한 문장 발음 열을 가지고 있으며 의미의 구분은 오직 피치의 변화 등 음성에 서 나타낼 수 있는 물리적 변화가 있어야 가능하다. 내포문 작 용역과 모문 작용역이 모두 가능한 ‘궁금하다'를 이용한 세 문 장의 피치 변화를 프랏(Boersma \& Weenink, 2021)으로 나타내 면 그림 2와 같다.

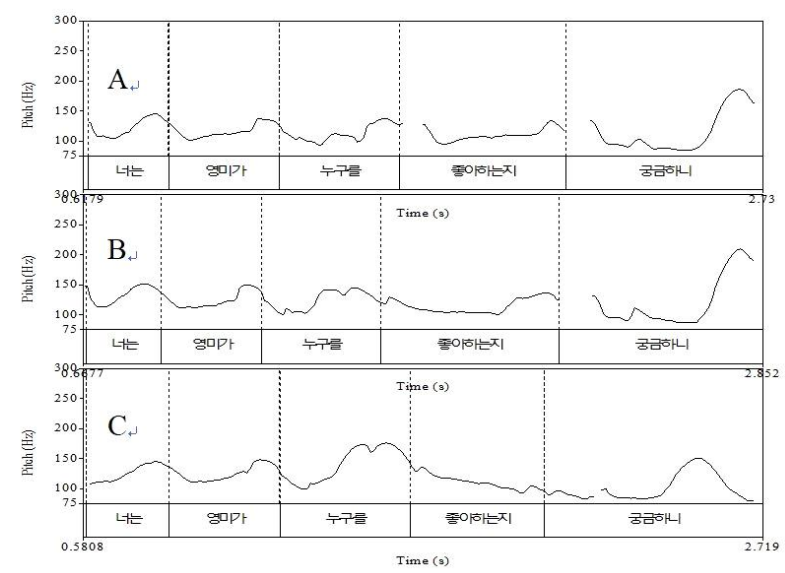

그림 2. ‘궁금하다' 자극 문장의 피치 곡선(A: 부정 대명사, B: 내포문 작용역, $\mathrm{C}$ : 모문 작용역)

Figure 2. Pitch contours of sentences with the verb '궁금하다(wonder)'(A: indefinite, B: embedded wh-scope, C: matrix wh-scope)

Jun (1993)에서 주장하듯, 유성음화가 일어나는 운율 단위는 강세구 내부이므로, ‘좋아하는지’의 좌우 경계에서 모두 유성음 화를 찾을 수 있는 그림 2 의 $\mathrm{C}$ 는 결과적으로 강세구 경계가 해 지되어 ‘누구를'에서 시작된 강세구 왼쪽 경계는 문장이 끝나는 곳의 억양구 경계와 오른쪽 경계를 일치시키게 된다. 이는 의문 사 구임을 확인시킴과 동시에 Richards(2010)에서 주장하듯이, 작용역이 모문이 되도록 모문 동사 ‘궁금하니'의 왼쪽 강세구 (또는 ‘좋아하는지’의 오른쪽) 경계도 해지되어 연속적으로 두 개의 강세구 경계가 해지된다고 할 수 있다. 이와 함께, 모문 작 용역의 ‘누구를'에 나타난 F0는 부정 대명사와 내포문 작용역 에서의 F0보다 더 높게 나타난 것으로 보아 명백히 의문사 구임 과 동시에 모문 작용역을 나타내는 지표로 볼 수 있다.

이에 비하여 그림 2의 $\mathrm{A}$ 는 모든 어절에서 강세구 경계가 나 타나며 $\mathrm{B}$ 는 ‘좋아하는지'의 오른쪽 강세구 경계에 $\mathrm{Ha}$ 경계 피 치가 보이고, ‘궁금하니'의 첫 연구개 폐쇄 연음(lax)이 유성화 되지 않아 분명히 강세구 경계가 있음을 알려주고 있다. 다만 ‘누구를'의 오른쪽 경계는 ‘좋아하는지'의 첫 자음이 유성화되 어 강세구 경계 해지를 보이고 있다.

모문 동사의 억양구 경계에 나타나는 경계 톤에서도 설명 의 문문에서 나타나는 $\mathrm{HL} \%$ 로 그림 2의 $\mathrm{C}$ 는 모문 작용역이 설명 의문문임을 잘 나타내는 전형적인 억양 곡선이라 할 수 있다. 이와 관련하여 Jun \& Oh(1996)은 설명 의문문의 전형적인 경계
톤이 $\mathrm{HL} \%$ 가 아닌 $\mathrm{H} \%$ 그리고 주로 $\mathrm{LH} \%$ 로 실현된다고 보았다. 그러나 Kim et al.(2000)은 낮게 형성된 $\mathrm{H} \%$ 그리고 주로 $\mathrm{HL} \%$ 가 설명 의문문의 억양구 경계 톤임을 주장하였다. 이에 덧붙여, 본 연구와 유사한 주제를 다룬 두 연구 중 첫 번째인 Hwang (2007)의 자극 문장 운율 구조에서도 모문 작용역일 경우 예외 없이 모두 HL\%의 억양구 경계 톤을 보여주고 있으며, 마찬가지 로 Yoon(2010)은 'Rising'으로 표현된 억양구 경계 톤으로 만들 어진 자극에 피험자 모두 판정 의문문으로 해석했다는 결과를 보고하고 있다. 이런 면에서 억양구 경계 톤 $\mathrm{HL} \%$ 는 모문 작용 역을 나타내는 전형적인 패턴이라는 것이 매우 분명해 보인다. 이렇게 자극 문장의 운율 구조는 전달하고자 하는 문장의 의미 를 정확히 알려주는 전형적인 패턴으로 발화되었다.

\section{3. 청취 실험 절차}

피험자들은 먼저 실험의 방법에 대한 전반적인 설명을 청취 하였다. 즉, 문장이 발화되면 그 발화를 듣고 그것이 '네, 아니 오'로 대답을 요구하는 문장인지 아니면 ‘설명 의문문'인지 오 른쪽과 왼쪽의 'shift' 키를 통해 선택하도록 지시하였다. 실험 설명에서 설명 의문문의 의미도 예를 들어 설명하였다.

목표 자극 문장 7 개와 채움 문장 32 개 총 39 개의 청취 자극을 3 회에 반복하여 실시하였으며, 본 실험 전에 10 개의 채움 문장 으로 연습 기회가 주어졌다. 한 회 청취 실험이 끝나면 각자 5 분 의 휴식시간이 주어졌고, 휴식시간이 끝나면 피험자에게 휴식 시간이 종료되었음을 알리는 문자열이 컴퓨터 화면에 나타나 며, 준비되는 대로 'Enter'를 눌러 시작할 수 있도록 프로그래밍 하였다.

피험자의 각 자극 문장에 대한 의문문 종류 선택의 대답을 기 록, 엑셀 파일에 저장하고, 그와 함께 자극이 끝날 때부터 대답 을 선택하는데 걸리는 반응 시간도 기록, 저장하였다. 실험은 5 6명씩 동시에 실시되었으며 모두 동일 기종의 노트북을 사용 하였다. 피험자들은 모두 동일 기종의 밀폐형 헤드폰(AKG사 $\mathrm{K} 271 \mathrm{MKII})$ 을 착용하고 실험에 임했다. 실험 장소는 서울권 대 학의 한 연구소에서 실험에 방해받을만한 생활 소음 없이 진행 되었으며, 피험자에게 소정의 사례비를 지급하였다.

\section{4. 분석 대상 및 통계처리}

7 개의 자극 문장 중 분석의 대상은 ‘궁금하다'로 이루어진 4 종류의 문장이다. 따라서 피험자 1 명 당 총 3 회에 걸쳐 12 개의 분석 대상 자극 문장에 대하여 반응하게 되며 총 600 개( 12 개 $\times 50$ 명), 각 문장 당 150 개(600개/4 문장)의 대답과 반응 속도를 대상 으로 분석하였다.

600 개의 반응 중 피험자 1 명의 반응시간이 자극이 끝나기 전 에 키보드를 선택한 경우가 2회로 나타나 이 피험자의 의문문 판단과 그것의 반응 시간에 대한 신뢰성에 문제가 있다고 판단 하여 최종 분석에서 모두 제외하였다. 따라서 총 분석 대상은 600 개에서 1 명의 반응 12 개가 줄어든 588 개 이다.

먼저 각 자극 문장의 의문문 종류를 선택하는 대답이 얼마나 정확한지 살펴본 후, 반응 시간을 종속 변수로 하여 각 실험 회 
차에 따라 반응 시간이 변하는지와, 의문문의 종류에 따라 반응 시간이 달라지는지, 두 가지 요인을 각각 독립변수로 하여 이원 반복측정분산분석(two-way repeated measures ANOVA)을 통계 프로그램인 R을 사용하여 분석하였다(R Core Team, 2020).

\section{4. 실험 결과 및 논의}

\section{1. 의문문 종류 선택의 오류 분석}

‘궁금하다'로 이루어진 각 문장의 의문문 종류 선택에 대하 여 기대하는 대답과 일치한 의문문 종류를 선택한 수와 그렇지 못한 수를 표 2에 나타내었다.

표 2. 문장 종류에 따른 기대 대답과 정오 답변 수 Table 2. The expected answers and the correct number of answers depending on the sentence types

\begin{tabular}{c|c|c|c|c}
\hline 문장 종류 & 기대 대답 & 정답 & 오답 & 합계 \\
\hline 모문 작용역 & 설명 의문문 & $127(86.3 \%)$ & $20(13.6 \%)$ & 147 \\
\hline 내포문작용역 & 판정 의문문 & 146 & 1 & 147 \\
\hline 부정 대명사 & 판정 의문문 & 144 & 3 & 147 \\
\hline 명사 & 판정 의문문 & 146 & 1 & 147 \\
\hline \multicolumn{2}{c}{ 합계 } & $563(95.7 \%)$ & $25(4.25 \%)$ & 588 \\
\hline
\end{tabular}

전체 정답 비율은 문장의 종류와 관계없이 $95.7 \%$ 에 이른다. 눈에 띄는 오답 비율은 모문 작용역을 나타내는 문장에서 나타 난다. 부정 대명사에서의 오답에 비하면 약 7 배의 오답 비율을 보이고 있다. 만약 오답 20 개가 피험자 20 명에게서 3 회의 실험 중 한 번씩 잘못된 판정을 했다면 49명 중 20명(40.8\%)이 모문 작용역 해석을 받아들이는 것을 주저하고 있다고 할 수 있으며, 이는 두 가지로 나누어 생각해 볼 수 있다.

첫째 $40.8 \%$ 에 이르는 피험자의 모문 작용역 해석이 지금까지 알려진 운율 구조 조건, 즉 강세구 경계 해지와 의문사 구 돋들 림에 의존하지 않을 수 있는 가능성이다. 다시 말해서, wh-섬 제 약이 약화되어 모문 작용역 해석을 받아들일 수 있으나 실험에 사용된 자극 문장의 운율 구조로는 이를 달성할 수 없다는 것이 다. 그러나 비록 $40.8 \%$ 의 피험자가 자극의 운율 구조를 받아들 일 수 없다고 하더라도 나머지 약 $60 \%$ 의 피험자들은 동일 구조 를 wh-섬 제약 약화에 필요한 운율 구조로 받아들였다는 점을 생각해 볼 때 이를 받아들이기 어렵다.

둘째, 자극 문장의 운율 구조와 관계없이 $40.8 \%$ 의 사람들이 wh-섬 제약의 영향력에 지배된다고 볼 수 있을 것이다. 이러한 가정이 사실이라면 서울말에서 다수라고 할 수 없지만 적지 않 은 수의 사람들에게 여전히 wh-섬 제약이 작동하고 있다고 할 수 있다. 어느 방언에서 wh-섬 제약이 활성화할 수 있으나, 동일 방언 내에서 제약의 활성화와 약화가 약 40 대 60 의 비율로 나 타난다는 것을 상상하기 어렵다. 왜냐하면 동일 방언 화자에 내 재된 동일 제약이 어느 한 쪽, 즉 발현하거나 그렇지 않는, 어느 한 방향으로 우세하게 나타나지 않고 서로 경쟁적인 관계를 보 인다는 것은 문법의 완결성(integrity)을 저해하는 요소로 판단 되기 때문이다. 이에 20 개의 오답을 좀 더 면밀히 관찰할 필요
가 있으며, 이를 위해 피험자 별, 실험 회차별 오답 현황을 표 3 에 나타내었다.

표 3. 피험자 별 모문 작용역 오류 발견 실험 회차와 오류 합계

Table 3. Errors in the matrix scope interpretation depending on subjects and trials, and a total number of errors for each of the subjects

\begin{tabular}{c|c|c|c|c}
\hline 피험자 & 1회 & 2회 & 3회 & 오류합계 \\
\hline A1 & $\checkmark$ & & & 1 \\
\hline A2 & $\checkmark$ & & & 1 \\
\hline A3 & $\checkmark$ & & & 1 \\
\hline A4 & $\checkmark$ & & & 1 \\
\hline A5 & $\checkmark$ & & & 1 \\
\hline A6 & & $\checkmark$ & & 1 \\
\hline A7 & & $\checkmark$ & & 1 \\
\hline A8 & $\checkmark$ & $\checkmark$ & & 2 \\
\hline A9 & $\checkmark$ & $\checkmark$ & & 2 \\
\hline A10 & & $\checkmark$ & $\checkmark$ & 2 \\
\hline A11 & & $\checkmark$ & $\checkmark$ & 2 \\
\hline A12 & $\checkmark$ & & $\checkmark$ & 2 \\
\hline A13 & $\checkmark$ & $\checkmark$ & $\checkmark$ & 3 \\
\hline 오류합계 & 9 & 7 & 4 & 20 \\
\hline
\end{tabular}

3회의 실험 중 오류가 한 번씩 발견된 피험자는 모두 7명이며 2 회의 오류는 5 명, 모든 회차에서 판정 의문문으로 대답한 피험 자는 한 명으로 실제 오류가 발견된 피험자의 수는 총 13명으로, 실험 참가자 49 명의 $26.5 \%$ 에 그치고 있다. 또한 3 회 중 어느 한 회차에 오류가 있는 피험자도 대부분 첫 번째 실험 회차에서 오 류가 발견된다(7명 중 5명). 결과적으로 20개의 오답을 낸 피험 자는 총 13 명, 그 중 1 회차에 한하여 1 회 오답을 낸 5 명을 제외 한 8 명에게서 wh-섬이 여전히 제약으로 작용하여 wh-섬 제약 활성화 비율이 $16.3 \%$ 에 이른다고 볼 수 있다. 이러한 수치는 Yoon(2010)에서의 실험 결과와 비교해 볼 만 하다.

Yoon(2010: 633)은 두 개의 모문 작용역 설명 의문문으로 진 행한 청취 실험에서 첫 번째 문장은 40 명(1명 답변 제외) 중 14 명만이 모문 작용역 설명 의문문으로 이해하였고, 두 번째 문장 은 13명만이 모문 작용역으로 이해했다고 보고하였다. 평균적 으로 26.5 명(33.8\%)에게서 제약이 약화되었으며 wh-섬 제약 활 성화 비율은 $66.2 \%$ 에 이른다. 이는 위에서 20 개의 오답을 모두 각기 다른 피험자가 생산했을 경우보다도 월등히 더 큰 수치라 할 수 있다. 이미 살펴보았듯이, 동일 방언의 문법에서 동일 제 약이 경쟁적 관계를 보인다는 것은 이해하기 어려우며, 더구나 실험에 따라 wh-섬 제약 활성화가 더 높거나 또는 약화가 더 높 게 나타나는 모순적 결과를 보인다는 면에서 Yoon(2010)의 실 험 결과를 그대로 받아들이기 어렵다. 또한 ‘의문사 억양'으로 wh-섬 제약을 약화시킬 수 있다는 기존의 여러 연구와 배치되 는 결과라 할 수 있다.

이에 비하여 이 연구에서는 실제 20 개의 오답이 20 명이 아닌 13명에게서, 또한 일 회차의 오답을 제외하면 8명에게서만 나 타난 현상으로, 기존 연구의 ‘의문사 억양’을 통한 wh-섬 제약 약화가 $83.7 \%$ 라는 다수의 피험자에게서 나타나고, 비교적 적은 수의 피험자에게서 wh-섬 제약이 활성화되어 동일 문법에서 동 일 제약에 대한 반응이 어느 한 방향으로 우세하게 나타나리라 
는 기대를 충족시키고 있다.

표 3에서는 실험이 반복될수록 오류 수도 감소하는 변화를 볼 수 있다. 즉, 첫 번째 실험에서는 총 9회의 오류, 다시 말해서 9명에게서 오류가 나타났으나, 2회, 3회를 거듭하면서 7명, 4명 에게서 오류가 발견되어 지속적으로 wh-섬 제약이 활성화 되는 피험자의 수가 줄어드는 경향을 보여주고 있다. 이는 실험 횟수 가 증가하면서 피험자들이 설명 의문문 운율 구조를 이해하여 모문 작용역 해석을 받아들이는 것으로 볼 수 있다. 다시 말해 서 wh-섬 제약이 활성화 되어 문법성 판단에 결정적 역할을 하 는 것이 아니라 이미 대부분의 피험자들이 제약의 약화를 받아 들일 준비가 되어 있는 상태라고 할 수 있다. 이는 서울말에서 wh-섬 제약 약화가 기본 값(default value)으로 맞춰져 있을 가능 성을 보여준다고 할 수 있다. 3

종합하면, 이 실험의 오류 분석을 통해 다수의 피험자가 wh섬 제약의 약화를 보여주고 있는 반면, 비교적 소수의 피험자에 게서 wh-섬 제약의 활성화가 나타나고 있어 서울말도 동남 방 언과 마찬가지로 적절한 운율 구조로 발화된다면 모문 작용역 해석이 가능한 wh-섬 제약 약화 방언으로 볼 수 있다.

\section{2. 반응 시간과 오류 반응 분석}

자극 문장을 듣고 판정 또는 설명 의문문을 선택하는데 걸린 반응 시간을 자연로그(natural $\log$ )로 변환 후 다시 표준화하여 통계에 사용하였다. 그림 3에서와 같이 문장 종류별 상자 그림 (box plot)을 살펴보면 모문 작용역을 판단하는데 걸린 반응 시 간이 다른 어느 유형의 문장 보다 더 길다는 것을 알 수 있다. 좀 더 구체적으로 살펴보면, 모든 의문문의 종류 중에 명사가 사용 된 문장에서의 반응 시간이 가장 빠르고 모문 작용역 판단이 가 장 늦다는 것을 알 수 있고, 내포문 작용역과 부정 대명사의 판 단에는 반응 시간의 차이가 눈에 띄게 나타나지 않는 점 또한 알 수 있다. 각 실험 회차별 반응 시간에 있어서도 전반적으로 회가 거듭할수록 반응 시간이 조금씩 줄어드는 학습 효과도 찾 아볼 수 있다.

이러한 일반적인 차이를 이원반복측정분산분석을 이용하여 검증해 보았을 때, 의문문 종류에 따른 차이는 통계적으로 유효 한 것으로 $[F(2.39,74.24)=41.778, p<0.001]$, 실험 횟수에 따른 차 이도 유효한 것으로 나타났으나 $[F(2,62)=10.011, p<0.001]$, 두 요인에 대한 교호 효과는 유효하지 않았다 $[F(6,186)=0.977$, $p=0.44]$.

두 가지 주요인에 대한 차이가 나타났으므로 뒤이어 사후검 증(post-hoc test)을 실시하였다. 사후검증 방법은 'paired Bonferroni $t$-test'를 사용하였다. 예상대로 내포문 작용역과 부 정 대명사 의문문 문장에서의 반응 시간 차이는 나타나지 않았 고 그 외의 모든 짝에서 신뢰 수준 0.01 이하의 통계적 차이가 있음이 밝혀졌다. 동일한 방법을 사용하여 실험 횟수를 대상으
로 사후검증을 실시하였으며, 2회와 3회 사이에서의 차이는 나 타나지 않은 반면 1회와 2회, 그리고 1회와 3회 사이는 모두 $p<0.001$ 로 차이가 있는 것으로 나타났다.

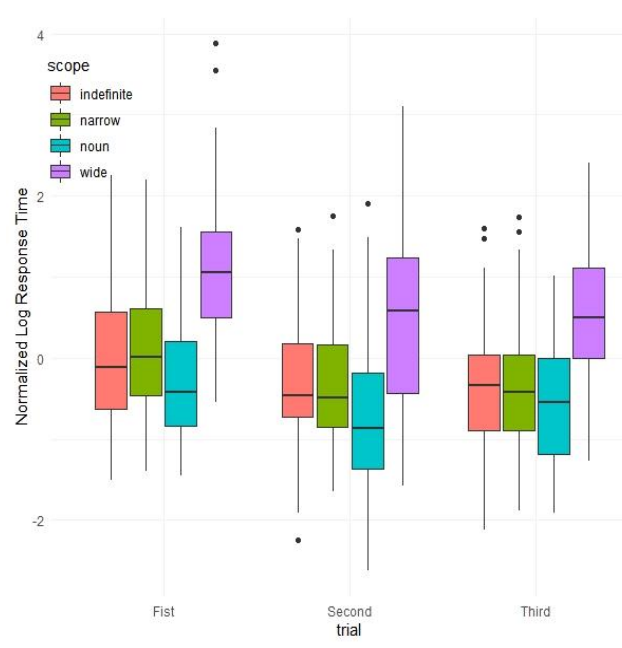

그림 3. 문장과 실험 횟수에 따른 반응 시간

Figure 3. Normalized log response time depending on sentence types and trials

모문 작용역 판단에서 오류가 나타난 피험자의 각 실험 횟수 별 반응 시간을 표 3의 오류 위치와 함께 표시하여 표 4에 나타 내었다. 이를 통해 오류가 줄어들면 반응 시간도 함께 줄어든다 는 것을 알 수 있으나, 피험자 별 정답과 오답 사이의 일관된 반 응 시간 관계는 발견할 수 없었다. 즉 피험자에 따라 오답에 대 한 반응 시간이 정답보다 빠르거나 느리게 나타나기도 한다. 그 러나 오류가 줄어들면 평균 반응 시간이 줄어든다는 것은 전반 적으로 오류에 소요되는 반응 시간이 조금 더 길다는 것을 보여 준다고 할 수 있다.

이미 그림 3 을 통해 보았지만, 모문 작용역 해석에 소요되는 시간이 길고 또 오류의 반응 시간이 대체로 길다는 것은 모문 작용역 판단에 '필요한 처리'가 다른 문장들에 비하여 더 시간 을 요구한다고 볼 수 있다. 즉 모문 작용역 해석에 필요한 조건 은 강세구 해지가 두 번(‘좋아하는지'의 좌, 우 경계) 일어나고, 의문사 구의 돋들림이 있어야 한다. 여기에 덧붙여 비록 모문 해석에 필요한 조건으로 검토되지 않았으나 그림 2의 $\mathrm{C}$ 에서 확 연히 나타나는 의문 종결어미의 억양구 경계 톤인 $\mathrm{HL} \%$ 도 모문 작용역 판단에 사용되었을 것으로 기대할 수 있다. 강세구 발현 또는 해지와 관련하여 모문 작용역 판단에 소요되는 필요 처 리, 시간만 보더라도, 모든 강세구 발현(그림 2의 A: 명사, 부정 대명사), 하나의 강세구 경계 해지(그림 2의 B: 내포문 작용역) 의 경우보다 수적으로 더 많은 요소를 처리해야하므로 더 많은 시간이 소요되는 것은 당연하다 할 것이다. 
표 4. 모문 작용역 해석에서 오류가 발생한 피험자의 회차 별 반응 속도와 평균(오류 발견 회차에 그림자 표시)

Table 4. Normalized log response time for subjects having errors in the interpretation of a matrix wh-scope sentence and the mean values of each trial (Shades represent errors found)

\begin{tabular}{c|c|c|c}
\hline 피험자 & 1회 & 2회 & 3회 \\
\hline $\mathrm{A} 1$ & 0.5266 & 1.0970 & -1.2746 \\
\hline $\mathrm{A} 2$ & 1.6882 & 0.9015 & 0.9221 \\
\hline $\mathrm{A} 3$ & 2.2459 & 2.2567 & 0.2509 \\
\hline $\mathrm{A} 4$ & 1.2638 & 1.5146 & -0.2108 \\
\hline $\mathrm{A} 5$ & 2.2298 & 1.4767 & 0.6587 \\
\hline $\mathrm{A} 6$ & -0.4917 & 0.7315 & -0.4242 \\
\hline $\mathrm{A} 7$ & 1.1437 & 1.6091 & 0.2897 \\
\hline $\mathrm{A} 8$ & -0.9289 & 0.7326 & 0.6707 \\
\hline $\mathrm{A} 9$ & 0.3737 & 0.6252 & 1.1157 \\
\hline $\mathrm{A} 10$ & 3.5484 & 2.5057 & -0.9850 \\
\hline $\mathrm{A} 11$ & 1.6940 & 2.6137 & 2.6905 \\
\hline $\mathrm{A} 12$ & 1.3138 & -0.4735 & 1.1549 \\
\hline $\mathrm{A} 13$ & 1.0769 & -0.0239 & 1.0709 \\
\hline 반응 시간 평균 & 1.2064 & 1.1965 & 0.6815 \\
\hline
\end{tabular}

비록 모문 작용역 문장에 대하여 잘못된 대답을 했다고 하더 라도 그에 대한 반응 시간은 판정 의문문에 비하여 월등히 길다 고 할 수 있다. 모문 작용역 판단에 걸린 시간과 유사한 정도로 긴 시간이 소요되었음에도 불구하고 다수의 피험자들은 모문 작용역으로 해석하는 반면 $16.3 \%$ 의 피험자들은 모문 작용역 해 석을 회피하는 결과를 보여주었다. 반응 시간으로 판단해 볼 때, wh-섬 제약의 영향을 받는 피험자들은 적극적으로 판정 의문문 을 선택했다기보다는 모문 작용역 자극이 적어도 설명 의문문 은 아니라는 의미에서 소극적으로 판정 의문문을 선택한 것으 로 해석하는 것이 타당해 보인다. 부연하자면, 적극적인 판정 의문문 선택은 다른 판정 의문문에 나타난 반응 시간과 유사한 반응 시간을 보일 것이라고 예상할 수 있으나 그렇지 않은 것으 로 보아 소극적 선택, 즉 설명 의문문(모문 작용역 해석)이라고 볼 수 없다는 것의 표현이라고 할 수 있다.

반응 시간 분석을 통하여 모문 작용역 판단에는 많은 부하가 들어가는 처리라는 것을 알 수 있다. 많은 처리 시간에도 모문 작용역으로 판단하는 피험자가 다수를 차지하고 있는 것으로 보아 서울말에서의 wh-섬 제약은 약화되어 나타나는 것이 일반 적이라고 주장할 수 있을 것이다. 그러나 여전히 몇몇 피험자들 은 wh-섬 제약이 타인에 비해 더 활발히 작동하는 문법을 내재 화 하고 있는 것으로 보인다.

\section{5. 결론}

wh-섬 제약의 실재에 대하여 청취 실험을 통해 서울말도 동 남 방언에서와 마찬가지로 적절한 ‘의문사 억양’이 주어지면 wh-섬 제약이 약화되는 방언임을 밝히고자 하였다. 다시 말해 서 모문 작용역으로의 해석을 받아들이는 서울말 청자가 그렇 지 않은 청자에 비해 다수를 차지한다고 할 수 있다. 실험의 회 차가 증가할수록 오답의 수가 줄어드는 경향으로 판단하건데 대부분의 청자들은 wh-섬 제약이 약화되는 문법을 내재화 하고
있다고 볼 수 있다.

또한 반응 시간 분석을 통해 모문 작용역 문장에 대한 판단에 상대적으로 긴 시간이 소요된다는 것을 알 수 있다. 그것은 ‘의 문사 억양’을 통해 실현되는 강세구 경계 해지, 의문사구 돋들 림 등, 처리해야할 요소가 다른 의문문 종류에 비해 더 많기 때 문인 것으로 보이며, wh-섬 제약이 활성화 되어 있는 청자의 경 우 그러한 운율 구조에도 불구하고 더욱 강력한 wh-섬 제약이 작동한다는 것을 간접적으로 보여준다고 할 수 있다.

아직 본격적으로 다루지는 않았으나 이 연구에서 모문 작용 역 문장의 억양구 경계 톤으로 사용된 $\mathrm{HL} \%$ 가 실제 모문 작용역 판단에 영향을 주었는지에 대한 연구가 필요하다. 마지막으로 Yun et al.(2020)은 서울말 화자가 내포문과 모문 작용역 문장을 서로 다른 운율 구조를 사용하여 발화하는지에 대해 의문을 제 기하였다. 그렇다면 wh-섬 제약이 청취와 발화에서 다른 양상, 즉 청취에서는 약화되는 반면 발화에서는 활성화되는 방식으 로 나타난다고 할 수 있는데, 이에 대한 적절한 추가적 연구가 필요하다.

\section{References}

Boersma, P., \& Weenink, D. (2021). Praat: Doing phonetics by computer [Computer program]. Retrieved from http://www. fon.hum.uva.nl/praat/

Choe, H. S. (1995). Focus and topic movement in Korean and licensing. In É. K. Kiss (Ed.), Discourse configurational languages (pp. 269-334). Oxford, UK: Oxford University Press.

Chung, D. (1996). On the representation and licensing of $Q$ and Q-dependents (Doctoral dissertation). University of Southern California, Los Angeles, CA.

Deguchi, M., \& Kitagawa, Y. (2002, April). Prosody and whquestions. Proceedings of the North East Linguistics Society. (NELS) (vol. 32, pp. 73-92). Amherst, MA.

Hong, S. (2004). On the nature of Korean wh-expressions. In R. Husted (Ed.), Essex graduate student papers in language and linguistics (Vol. 6, pp. 1-32). Colchester, UK: Unversity of Essex. Huang, C. J. (1982). Logical relations in Chinese and the theory of grammar (Doctoral dissertation). Massachusetts Institute of Technology, Cambridge, MA .

Hwang, H. (2007, September). Wh-phrase questions and prosody in Korean. Proceedings 17th JK Linguistic Conference (pp. 295-309). Tainan, Taiwan.

Hwang, H. K. (2006). Intonation patterns of wh-interrogatives in South Kyungsang Korean and Fukuoka Japanese. Eoneohak, 45, 39-59.

Hwang, H. K. (2011). The interaction of accent and wh-question intonation in Korean and Japanese. Language Research, 47(1), 45-70.

Hwang, H. K. (2015). Overriding syntactic islands with prosodically 
marked wh-scope in South Kyŏngsang Korean and two dialects of Japanese. Korean Linguistics, 17(1), 33-77.

Ishihara, S. (2002, January). Invisible but audible wh-scope marking: Wh-constructions and deaccenting in Japanese. Proceedings of the 21st West Coast Conference on Formal Linguistics (pp. 180-193). Somerville, MA: Cascadilla Press.

Ishihara, S. (2004). Prosody by phase: Evidence from focus intonation - wh-scope correspondence in Japanese. In S. Ishihara, M. Schmitz, \& A. Schwarz (Eds.), Interdisciplinary studies on information structure (Vol. 1, pp. 77-119). Potsdam, Germany: University of Potsdam.

Jun, S. (1993). The phonetics and phonology of Korean prosody (Doctoral dissertation). The Ohio State University, Columbus, $\mathrm{OH}$.

Jun, S., \& Oh, M. (1996). A prosodic analysis of three types of wh-phrases in Korean. Language and Speech, 39(1), 37-61.

Jung, Y. J. (2010). Syntax-phonology interface of wh-questions. Studies in Generative Grammar, 20(1), 549-576.

Kim, M. R., Shin, D. H., Choe, J. W., \& Kim, K. H. (2000). Pitch patterns of interrogative sentences in relation to the focus. Speech Sciences, 7(4), 203-217.

Kim, Y., \& Um, H., (2020). The interface of syntax and phonology in the Korean wh-constructions: Focusing on the North Kyeongsang dialect. Korean Language and Literature in International Context, 86, 69-93.

Kubo, T. (2005). Phonology-syntax interfaces in Busan Korean and Fukuoka Japanese. In S. Kaji (Ed.), Cross-linguistic studies on tonal phenomena (Vol. 4, pp. 195-209). Tokyo, Japan: Research Institute for Languages and Cultures of Asia and Africa.

Lee, M. K. (2001). A tonological study on the interrogative sentence of Gyeongbuk dialect. Hangeul, 252, 5-44.

Mathôt, S., Schreij, D., \& Theeuwes, J. (2012). OpenSesame: An open-source, graphical experiment builder for the social sciences. Behavior Research Methods, 44(2), 314-324.

Miyagawa, S. (2004). On the nature of weak islands (Master's thesis). Massachusetts Institute of Technology, Cambridge, MA.

Park, S., Kim, K., \& Yun, W. (2020). On the intonation and syntactic interpretation of the interrogatives with an embedded wh-clause in Korean: With special reference to the Daegu-North Gyeongsang Korean and the Seoul Korean. Studies in Modern Grammar, 107, 73-101.

R Core Team (2020). R: A language and environment for statistical computing (version 3.6.2) [Computer software]. Vienna, Austria: R Foundation for Statistical Computing. Retrieved from https:// www.R-project.org/

Richards, N. (2010). Uttering trees. Cambridge, MA: MIT Press.

Ross, J. R. (1967). Constraints on variables in syntax (Doctoral dissertation). Massachusetts Institute of Technology, Cambridge,
MA.

Suh, J. M. (1987). A study of interrogative sentences in Korean. Seoul, Korea: Top.

Um, H., \& Kim, Y. H. (2020). On the scope and prosody of wh-phrases in North Gyeongsang Korean. Studies in Modern Grammar, 107, 23-41.

Yun, J. (2019). Meaning and prosody of wh-indeterminates in Korean. Linguistic Inquiry, 50(3), 630-647.

Yoon, J. M. (2010). A note on the controversy over the nature of wh-island effects of wh-in-situ questions in Korean. Studies in Generative Grammar, 20(4), 627-654.

Yun, W., Kim, K., \& Park, S. (2020). A prosodic cue representing scopes of wh-phrases in Korean: Focusing on North Gyeongsang Korean. Phonetics and Speech Sciences, 12(3), 41-53.

- 윤원희 (Weonhee Yun) 교신저자

계명대학교 영어영문학과 부교수

대구시 달구벌대로 1095

Tel: 053-580-5134

Email: whyun@kmu.ac.kr

관심분야: 실험음성학, 코퍼스 음성학 


\title{
서울말의 wh-섬 제약 지각 연구
}

\author{
윤 원 희
}

계명대학교 영어영문학과

\section{국문초록}

wh-섬 구조는 내포문에 있는 의문사 구가 모문의 작용역을 갖을 수 없도록 하는 제약이다. 서울말에서 내포문 의문 사 구가 모문의 작용역으로 해석할 수 없다고 알려져 있으나 의문사 억양으로 발화될 경우 모문 작용역 해석도 가 능하다고 보고되었다. 청취 실험을 통하여 서울말에서 의문사 구의 모문 작용역 해석이 가능한지 알아보았다. 내 포문에 ‘누구를'을 넣어 만든 세 종류의 의문문, 즉 부정 대명사와 내포문 작용역을 갖는 판정 의문문과 의문사 억 양으로 발화된 모문 작용역 해석이 가능한 설명 의문문을 자극으로 준비하고 비교를 위해 일반 명사를 사용한 판 정 의문문 문장도 함께 실험하였다. 피험자는 자극 문장을 듣고 '네/아니오'를 선택하거나 아니면 설명 의문문을 선택하도록 지시하였다. 피험자의 대답과 함께 선택에 소요된 반응 시간을 함께 기록하여 함께 분석하였다. 분석 결과 $83.7 \%$ 의 피험자가 모문 작용역 해석을 받아들이는 결과를 보여주었고 반응 시간에서 모문 작용역 문장에 대 한 선택이 정답과 오답을 포함하여 가장 긴 소요 시간을 보여주었다. 이를 통해 서울말은 약한 wh-섬 제약이라고 할 수 있다.

핵심어: 통사-음운 접합면, 의문사 억양, 의문사 작용역, 반응 시간, wh-섬 제약, 지각 실험

\section{참고문헌}

김미란, 신동현, 최재웅, 김기호(2000). 초점과 관련된 의문문 억

양 패턴 실험. 음성과학, 7(4), 203-217.

김용하, 엄홍준 (2020). 한국어 $\mathrm{Wh}$-구문에서의 통사론과 음운론 의 접합영역: 경북 방언을 중심으로. 국제어문, $86,69-93$.

박선우, 김기태, 윤원희 (2020). 한국어 설명의문문의 억양과 통 사적 해석: 대구 · 경북방언과 서울방언의 비교. 현대문법연 구, 107, 73-101.

서정목(1987). 국어 의문문 연구: : 慶南方言 과 中世國語 의 WH현상을 중심으로. 서울: 탑출판사.

엄홍준, 김용하 (2020). 경북 방언의 의문사 작용역과 운율. 현대 문법연구, 107, 23-41.

윤원희, 김기태, 박선우 (2020). 한국어 의문사 작용역을 나타내 는 운율 단서: 경북 방언을 중심으로. 말소리와 음성과학, 12(3), 41-53.

이문규 (2001). 경북 방언 의문문의 성조 연구. 한글, $252,5-44$. 